\title{
Influenza Infection Induces Neuroinflammation, Alters Hippocampal Neuron Morphology, and Impairs Cognition in Adult Mice
}

\author{
Heidi A. Jurgens, ${ }^{1,2}$ Kaushik Amancherla, ${ }^{2}$ and Rodney W. Johnson ${ }^{1,2,3}$ \\ ${ }^{1}$ Neuroscience Program, ${ }^{2}$ Integrative Immunology and Behavior Program, and ${ }^{3}$ Department of Animal Sciences, University of Illinois, Urbana, \\ Illinois 61801
}

Influenza is a common and highly contagious viral pathogen, yet its effects on the structure and function of the CNS remain largely unknown. Although there is evidence that influenza strains that infect the brain can lead to altered cognitive and emotional behaviors, it is unknown whether a viral strain that is not neurotropic ( $\mathrm{A} / \mathrm{PR} / 8 / 34)$ can result in a central inflammatory response, neuronal damage, and neurobehavioral effects. We hypothesized that neuroinflammation and alterations in hippocampal neuron morphology may parallel cognitive dysfunction following peripheral infection with live influenza virus. Here, we show that influenza-infected mice exhibited cognitive deficits in a reversal learning version of the Morris water maze. At the same time point in which cognitive impairment was evident, proinflammatory cytokines (IL-1 $\beta$, IL-6, TNF- $\alpha$, IFN- $\alpha$ ) and microglial reactivity were increased, while neurotrophic (BDNF, NGF) and immunomodulatory (CD200, CX3CL1) factors were decreased in the hippocampus of infected mice. In addition, influenza induced architectural changes to hippocampal neurons in the CA1 and dentate gyrus, with the most profound effects on dentate granule cells in the innermost portion of the granule cell layer. Overall, these data provide the first evidence that neuroinflammation and changes in hippocampal structural plasticity may underlie cognitive dysfunction associated with influenza infection. In addition, the heightened inflammatory state concurrent with reduced neurotrophic support could leave the brain vulnerable to subsequent insult following influenza infection. A better understanding of how influenza impacts the brain and behavior may provide insight for preventing inflammation and neuronal damage during peripheral viral infection.

\section{Introduction}

Influenza remains a leading cause of illness and death throughout the world, making it a serious health concern as well as a significant economic burden. While most people fully recover from influenza infection, the potential short-term and long-term consequences on CNS function are unknown. Neurological and cognitive effects associated with influenza infection have been reported throughout history (following the 1918 "Spanish flu"9), as well as during the recent novel influenza A HIN1 pandemic, but the mechanisms underlying these symptoms remain unclear [Ravenholt and Foege, 1982; Studahl, 2003; Centers for Disease Control and Prevention (CDC), 2009; González-Duarte et al., 2010]. Most influenza strains, including those responsible for pandemics, are considered nonneurotropic (Schlesinger et al., 1998; Kobasa et al., 2007; Wang et al., 2010), suggesting that neurological symptoms associated with influ-

Received Dec. 21, 2011; revised Jan. 20, 2012; accepted Jan. 25, 2012.

Author contributions: H.A.J. and R.W.J. designed research; H.A.J. and K.A. performed research; H.A.J. analyzed data; H.A.J. and R.W.J. wrote the paper.

This research was supported by National Institutes of Health Grant AG016710 (R.W.J.). We thank Dr. Janice M. Juraska (Department of Psychology, University of Illinois Urbana-Champaign) for help with the neuron morphology data and Dr. Jeffrey A. Woods (Department of Kinesiology and Community Health, University of Illinois Urbana(hampaign) for help with the mouse model of influenza infection.

Correspondence should be addressed to Rodney W. Johnson, 4 Animal Sciences Laboratory, 1207 W. Gregory Drive, University of Illinois at Urbana-Champaign, Urbana, IL 61801. E-mail: rwjohn@illinois.edu.

DOI:10.1523/JNEUROSCI.6389-11.2012

Copyright $\odot 2012$ the authors $\quad 0270-6474 / 12 / 323958-11 \$ 15.00 / 0$ enza infection are not a result of direct viral invasion into the CNS, but instead may be due to neuroinflammation induced by peripheral viral infection.

Previous work from our laboratory and others has shown that activation of the peripheral innate immune system induces production of cytokines including interleukin- $1 \beta$ (IL-1 $\beta$ ), IL-6, and tumor necrosis- $\alpha$ (TNF- $\alpha$ ) within the brain that can have deleterious effects on cognitive and emotional behavior (Sparkman et al., 2006; Chen et al., 2008; Dantzer et al., 2008; Yirmiya and Goshen, 2011). Inflammatory cytokines can negatively affect hippocampal function by directly impairing long-term potentiation (LTP) (Lynch, 2002; Pickering and O'Connor, 2007), and via the inhibition of neurotrophins (Tong et al., 2008), which are important for neuronal survival/ function, synaptic plasticity and memory formation (Poo, 2001; Tyler et al., 2002; Minichiello, 2009). In addition, changes in hippocampal neuron morphology have been reported following both peripheral and central administration of lipopolysaccharide (LPS), a component of Gram-negative bacteria that induces an innate immune response (Milatovic et al., 2003; Richwine et al., 2008). As alterations in dendritic branching and spine density can affect synaptic plasticity (Neves et al., 2008; Kasai et al., 2010), inflammationinduced changes in neuronal complexity may underlie functional deficits in hippocampal-dependent learning and memory.

Given that viral pathogens such as influenza are common and highly contagious, it is important to assess the effects of peripheral viral infection on CNS structure and function. It is currently un- 
known whether infection with influenza virus can result in a central inflammatory response, neuronal damage, and cognitive dysfunction. Therefore, the goal of this study was to use a mouse model of influenza to determine the impact of peripheral viral infection on hippocampal structure and function. We focused on the hippocampus because it exhibits a high degree of plasticity (Leuner and Gould, 2010), is vulnerable to neuroinflammation (Vitkovic et al., 2000; Lynch, 2002), and plays an important role in cognitive function (Bird and Burgess, 2008). We found that mice infected with live influenza A/PR8/34 (H1N1) exhibited increased hippocampal neuroinflammation and cognitive deficits that were paralleled by the loss of neurotrophic factors and significant alterations in CA1 and dentate gyrus neuron morphology. These findings are the first to suggest that altered hippocampal structural plasticity may underlie cognitive impairment during influenza infection.

\section{Materials and Methods}

Animals. For all studies, adult (4-6 months old) male BALB/c mice from our in-house colony were used. Mice were individually housed in polypropylene cages under a reverse $12 / 12 \mathrm{~h}$ light/dark cycle at $24^{\circ} \mathrm{C}$ and given ad libitum access to food and water. All animal care and experimental procedures are in accordance with the National Institutes of Health Guidelines for the Care and Use of Laboratory Animals and approved by the University of Illinois Institutional Animal Care and Use Committee.

Mouse viral infection. Mouse-adapted human influenza A/Puerto Rico/8/34 (H1N1) virus was a generous gift from Dr. John Sheridan (The Ohio State University, Columbus, $\mathrm{OH}$ ). Mice were lightly anesthetized with isoflurane and intranasally (i.n.) inoculated with 1 hemagglutinating unit (HAU) of influenza A/PR/8/34 virus in $50 \mu$ l of sterile PBS. Control animals were inoculated with $50 \mu \mathrm{l}$ of sterile PBS, i.n. Use of isoflurane anesthesia allowed for quick recovery $(<2 \mathrm{~min})$ and accurate delivery of viral dose. Following viral infection, mice were monitored daily for signs of morbidity including response to handling, food intake, and physical appearance (ruffled fur, huddled, or hunched behavior). In addition, changes in body weight and locomotor activity were used as more objective measures of disease progression. In mouse models of influenza, weight loss is considered a reliable way to track disease progress (Matsuoka et al., 2009). Body weight was measured at the same time daily (between 09:00-10:00 AM) and percentage change from initial body weight (day 0) was calculated. Previous studies (Lowder et al., 2005) have shown that during influenza infection, mice can lose a substantial amount of body weight (30-35\%) and still recover, however, as an established humane endpoint (Olfert and Godson, 2000), mice that reached a $30 \%$ loss of their initial body weight were killed (day 7 after inoculation).

Influenza virus M1 expression. To determine viral infection over the time course of influenza disease progression, a group of mice ( $n=4-5$ per group; control vs influenza) were inoculated and lung and brain tissue was collected at 1, 4, and $7 \mathrm{~d}$ after inoculation for measurement of mRNA expression of influenza matrix (M1) protein. Since M1 is conserved among mouse-adapted influenza viruses and is an internal protein within the viral envelope, M1 mRNA correlates with virus levels in infected tissues (Fouchier et al., 2000; Nogusa et al., 2008). In addition, the sensitivity of RT-PCR allows for detection of very low levels of the virus (Ward et al., 2004).

Locomotor behavior. In a cohort of mice ( $n=5-6$ per group; control vs influenza), spontaneous locomotor activity was measured before intranasal inoculation (day 0 ), and for $7 \mathrm{~d}$ following inoculation to investigate influenza-induced sickness behavior. Behavioral testing was conducted during the dark phase (between 09:00-11:00 A.M.) of the photoperiod under infrared lighting to aid video recording. Mice were maintained in their home cage and locomotor activity was video recorded during $5 \mathrm{~min}$ tests. A computerized animal tracking system (Ethovision; Noldus Information Technologies) was used to measure total distance moved during the testing period. At $7 \mathrm{~d}$ after inoculation, mice were killed and brains were collected for immunohistochemistry (detailed methods for immunohistochemistry are below).

Morris water maze. In a separate study, mice ( $n=10-12$ per group; control vs influenza) were inoculated and the effects of influenza on spatial learning and memory were assessed in a reversal learning version of the Morris water maze. In this hippocampal-dependent task, the animal must learn to use distinctive distal visuospatial cues surrounding the pool to navigate a direct path to the hidden platform (Morris, 1984; D'Hooge and De Deyn, 2001). The Morris water maze (MWM) consisted of a circular pool $\left(100 \mathrm{~cm}\right.$ diameter, $\left.23-25^{\circ} \mathrm{C}\right)$ with a transparent round platform ( $10 \mathrm{~cm}$ diameter) hidden $0.5 \mathrm{~cm}$ below the surface of the water. Mice were inoculated (day 0 ) and $2 \mathrm{~d}$ later began a $5 \mathrm{~d}$ acquisition phase (day 2-6 after inoculation). The platform remained in a constant location during the acquisition testing. Animals were placed on the platform for $30 \mathrm{~s}$ preceding the start of each testing session. The trials were conducted using a pseudorandom protocol in which mice were placed in the water in one of three preset entry locations. Mice were allowed to swim freely for $60 \mathrm{~s}$ or until the platform was reached. If the platform was not located during the $60 \mathrm{~s}$, mice were guided to the platform and allowed to remain for $30 \mathrm{~s}$. After completion of three consecutive trials, mice were placed in their home cage under a heat lamp to dry for $10 \mathrm{~min}$. On day 7 after inoculation ( $24 \mathrm{~h}$ after the last day of acquisition testing), the platform was removed and mice received a $30 \mathrm{~s}$ probe trial to assess spatial memory for the platform location. Following the probe trial, mice were subjected to a reversal test in which the hidden platform was moved to the opposite quadrant of the pool, but all distal visual cues remained constant. Animals were placed on the platform for $30 \mathrm{~s}$ preceding the start of the reversal test and given three trials to locate the platform in the new target quadrant. Reversal learning measures how quickly an animal is able to extinguish their initial learning of the position of the platform and acquire a direct path to the new location (Vorhees and Williams, 2006). A video camera in conjunction with a computerized animal tracking system (Ethovision; Noldus Information Technologies) was used to record swim speed, latency to the platform, and distance swam (pathlength to the platform).

Quantitative real-time PCR. Mice were killed by $\mathrm{CO}_{2}$ asphyxiation and tissue samples were quickly collected and stored in RNAlater at $-80^{\circ} \mathrm{C}$. Total RNA was isolated from homogenized tissue using the Tri Reagent protocol (Sigma). A QuantiTect Reverse Transcription Kit (Qiagen) was used for CDNA synthesis with integrated removal of genomic DNA contamination according to the manufacturer protocol. Quantitative real-time PCR was performed using the Applied Biosystems Assay-on Demand Gene Expression protocol. In short, cDNA was amplified by PCR where a target cDNA [IL- $1 \beta$, IL- 6 , TNF- $\alpha$, interferon- $\alpha$ (IFN- $\alpha$ ), IFN- $\beta$, IFN- $\gamma$, major histocompatibility complex (MHC class II), brain-derived neurotrophic factor (BDNF), nerve-growth factor (NGF), CD200, CX3CL1 (fractalkine), and influenza matrix M1] and a reference cDNA (glucose-3 phosphate dehydrogenase) were amplified simultaneously using an oligonucleotide probe with a $5^{\prime}$ fluorescent reporter dye (6-FAM) and a $3^{\prime}$ quencher dye (NFQ). PCRs were performed at the following conditions: $50^{\circ} \mathrm{C}$ for $2 \mathrm{~min}, 95^{\circ} \mathrm{C}$ for $10 \mathrm{~min}$, followed by 40 cycles of $95^{\circ} \mathrm{C}$ for $15 \mathrm{~s}$, and $60^{\circ} \mathrm{C}$ for $1 \mathrm{~min}$. Fluorescence was determined on an ABI PRISM 7900HT-sequence detection system (PerkinElmer). Data were analyzed using the comparative threshold cycle $(\mathrm{Ct})$ method, and results are expressed as fold change (Schmittgen and Livak, 2008).

Immunohistochemical staining and quantification. For determination of change in microglial reactivity, a group of mice $(n=5-6$ per treatment group; control vs influenza) were infected and brains were collected $7 \mathrm{~d}$ after inoculation for immunohistochemical staining of Iba-1 (ionized calcium binding adaptor molecule 1) expression. Mice were deeply anesthetized via $\mathrm{CO}_{2}$ inhalation and transcardially perfused with $2 \mathrm{~mm}$ EDTA saline followed by $4 \%$ paraformaldehyde, and whole brains were quickly removed. Brains were blocked at the optic chiasm (anterior, posterior) and postfixed over $2 \mathrm{~d}$ in $4 \%$ paraformaldehyde, and then paraffin embedded. Coronal sections $(4 \mu \mathrm{m})$ were cut on a microtome and stained for Iba-1 at the level of the hippocampus. Sections were dewaxed and rehydrated through xylene and alcohols and were incubated in citrate buffer, $\mathrm{pH} \mathrm{6}$, and microwaved for $10 \mathrm{~min}$. Endogenous peroxidase was eliminated by incubating sections in $3 \% \mathrm{H}_{2} \mathrm{O}_{2} /$ methanol for $15 \mathrm{~min}$. 
Sections were washed in PBS and blocked with $5 \%$ normal goat serum in PBS before overnight incubation at $4^{\circ} \mathrm{C}$ with the primary antibody at 1:1600 dilution in $5 \%$ blocking serum. The sections were washed, and then incubated with biotinylated goat anti-rabbit antibody (1:500 in 5\% blocking serum) for $1 \mathrm{~h}$. Staining was visualized using the $A B C$ method with $3,3^{\prime}$ diaminobenzidine $(\mathrm{DAB})$ as the chromogen. Sections were counterstained with hemotoxylin. Isotype-matched IgG was used as negative control. Brains were coded before sectioning to ensure that experimenters were blind to treatments.

Alterations in microglia reactivity were quantified using both digital image analysis (DIA) (Donnelly et al., 2009) to determine the area of Iba-1 immunostaining, and manual cell counts to quantify the number of Iba-1positive cells. Iba-1 expression was quantified in the CA1, CA3, and dentate gyrus (DG) regions of the dorsal hippocampus (bregma -1.46 to -2.46$)$. For each animal, eight images were taken from each hippocampal region (CA1, CA3, and DG) at $40 \times$ magnification. For DIA, a threshold for Iba-1-positive staining was determined and ImageJ software (http://rsbweb.nih.gov/ij/) was used to quantify the area of thresholded material within a given region. Proportional area was calculated as the percentage area in the positive threshold relative to total area for each image. For cell counts, the number of Iba-1-positive cells was determined for each section and expressed as mean number of cells $/ \mathrm{mm}^{2}$. To obtain an estimate of the average size of the Iba-1-positive cells, the average area of Iba-1-positive thresholded material was divided by the number of Iba-1-positive cells for each image (Tynan et al., 2010).

Hippocampal neuronal architecture. For determination of the effect of influenza on hippocampal neuronal architecture, a group of mice ( $n=5-6$ per treatment group; control vs influenza) were inoculated, and, at $7 \mathrm{~d}$ after inoculation, were killed by $\mathrm{CO}_{2}$ asphyxiation and whole brain was quickly removed and processed for Golgi-Cox staining as described previously (Markham et al., 2005; Richwine et al., 2008). Briefly, whole brain was submerged in Golgi-Cox solution for $11 \mathrm{~d}$, at which time test slices were taken to determine whether neurons were well filled. The brain was then coronally blocked at the optic chiasm and dehydrated. Brains were embedded in $12 \%$ celloiden and $150-\mu$ m-thick coronal sections were cut on a microtome. Slices were developed according to (Glaser and Van der Loos, 1981) and mounted on glass slides. Brains were coded before sectioning to ensure that experimenters were blind to treatments.

To evaluate hippocampal neuron morphology, a Zeiss Axio Imager A.1 microscope and a computer-based system (Neurolucida; MicroBrightField) was used to generate three-dimensional neuron tracings that were subsequently visualized and analyzed using NeuroExplorer (MicroBrightField). In order for a neuron to be selected the following four criteria were met: (1) neuron was in the area of interest, (2) neuron was distinct from other neurons to allow for identification of dendrites, (3) neuron was not truncated, and (4) neuron exhibited dark, well filled staining throughout (Gould et al., 1990). For each animal, pyramidal cells in the CA1 region (Fig. $1 A$ ) and granule cells in the suprapyramidal blade of the dentate gyrus (Fig. $1 D$ ) were traced in the dorsal hippocampus (bregma -1.46 to $-2.70)$ at $100 \times$ magnification. For each reconstructed neuron, an estimate of dendritic complexity was obtained using the Sholl ring method. A 3D Sholl analysis was performed in which concentric spheres of increasing ra-
B

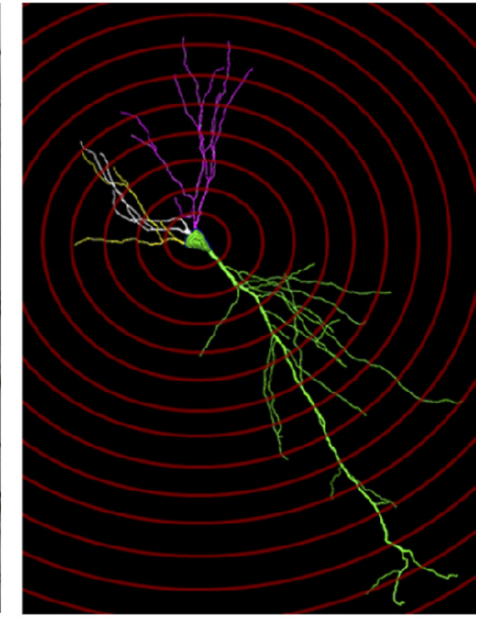

D

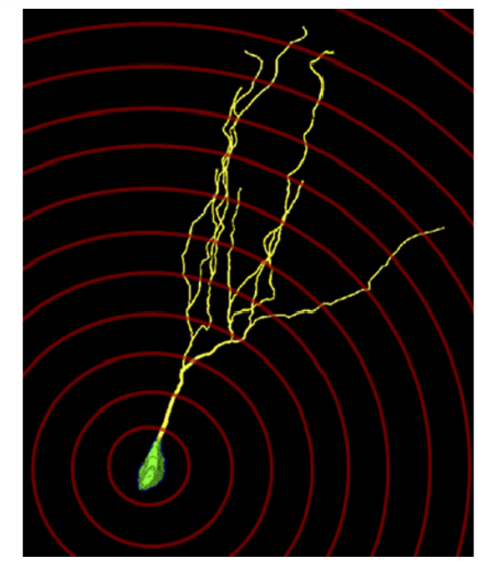

Figure 1. $A-D$, Representative examples of Golgi-stained neurons along with corresponding 3D reconstruction and Sholl ring analysis in the $C A 1(\boldsymbol{A}, \boldsymbol{B})$ and dentate gyrus $(\boldsymbol{C}, \boldsymbol{D})$ subfields of the hippocampus. Arrows indicate neuron selected for tracing. Magnification $=20 \times$; scale bars, $20 \mu \mathrm{m}$.

dius (in $20 \mu \mathrm{m}$ increments) were layered around the cell body until dendrites were completely encompassed (Fig. $1 B, D$ ). The number of dendritic intersections at each increment was counted, and results were expressed as total intersections and the number of intersections per radial distance from the soma. For CA1 pyramidal neurons ( $n=4-5$ cells per animal), both the apical and basal trees were traced, and morphological measurements were analyzed separately. As previous work has shown that the morphology of dentate gyrus granule neurons varies by soma location within the granule cell layer (GCL) (Green and Juraska, 1985; Wang et al., 2000), for each animal, 5-6 cells located in the inner one-third of the GCL (near the hilus), and 5-6 neurons located in the remaining two-thirds of the granule cell layer (near the molecular layer) were traced for a total of 10-12 dentate granule cells per animal.

For all neurons, spine density was measured on the same dendritic branches used for Sholl analysis. For CA1 pyramidal neurons, dendritic spine density was measured on three dendritic segments from both the basal and apical tree. For the basal tree, spines were counted along 10-20 $\mu \mathrm{m}$ segments of $2-5^{\circ}$ order branches located at least $50 \mu \mathrm{m}$ away from the cell body. For the apical tree, spines were counted along 10-20 $\mu \mathrm{m}$ segments of tertiary oblique apical branches. For dentate gyrus granule cells, dendritic spine density was measured on three dendritic segments of $2-5^{\circ}$ order branches located at least $50 \mu \mathrm{m}$ away from the cell body. All measurements of spine density were taken from $1-2-\mu \mathrm{m}$-thick dendritic segments to minimize the number of spines hidden by the dendritic shaft and ensure that the number of hidden spines was proportional across all segments counted and among treatment groups. The total number of 

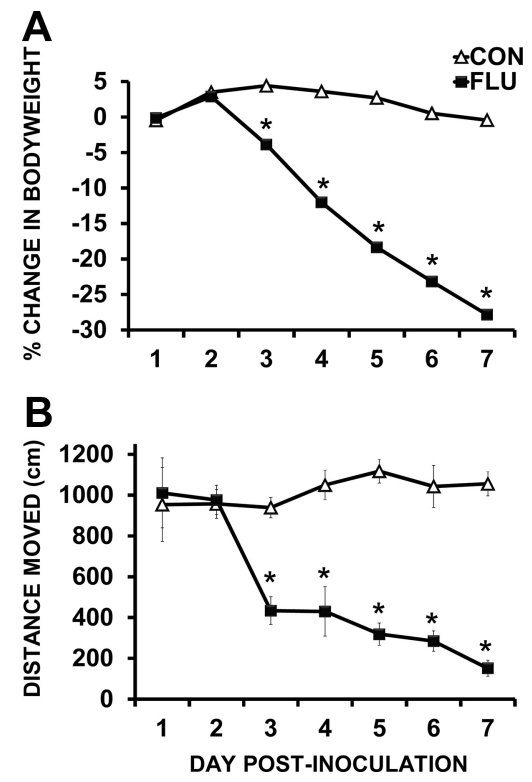

Figure 2. Sickness behavior following influenza infection. $A, B$, Influenza-infected mice (FLU) lost a significant amount of body weight $(\boldsymbol{A})$, and locomotor activity rapidly declined $(\boldsymbol{B})$ over the course of influenza infection. Data are represented as means \pm SEM [ ${ }^{*} p<0.05$ compared with controls (CON)].

dendritic spines visible along both sides of the segment was counted and expressed as number of spines per micron of dendrite.

Statistical analysis. Differences in body weight, locomotor behavior, acquisition in the water maze, reversal testing trials, and Sholl plots were tested with a repeated-measures ANOVA using treatment (control vs influenza infection) as the between-subjects factor. The within-subjects factors used were as follows: day after inoculation (body weight and locomotor activity), testing day (water maze acquisition), trial (reversal testing), and radial distance from the soma (Sholl plots). Iba-1 immunohistochemistry data were subjected to a two-way ANOVA in which treatment (control vs influenza) and hippocampal region (CA1, CA3, and DG) were independent variables. Morphological data (Sholl analysis and spine density) for dentate gyrus granule cells were subjected to a two-way ANOVA in which treatment (control vs influenza) and soma location in the granule cell layer (inner vs outer) were independent variables. Since influenza M1 expression was nondetectable in control samples, Student's $t$ test using Fisher's least significant differences was used to determine whether means for days after inoculation were significantly different from each other. All other data [hippocampal gene expression, water maze reversal test and probe trial, and CA1 apical and basal tree morphology (Sholl analysis and spine density)] were subjected to a one-way ANOVA in which treatment (control vs influenza) was the independent variable. When the ANOVAs revealed a significant main effect or interaction between main factors, post hoc Student's $t$ test using Fisher's least significant differences was used to determine whether treatment means were significantly different from one another $(p<0.05)$. All data are presented as means \pm SEM.

\section{Results}

\section{Influenza-induced sickness behavior and viral expression}

Changes in body weight and locomotor behavior were used to measure the sickness response to influenza infection. For the body weight data, repeated-measures ANOVA revealed an effect of treatment $(p<0.0001)$, day $(p<0.0001)$, and treatment $\times$ day interaction $(p<0.0001)$ indicating that mice infected with influenza lost more body weight than controls over the 7 day time course after inoculation (Fig. 2 A). The data for locomotor activity followed the same pattern, with an effect of treatment $(p=0.0007)$, day $(p<0.0001)$, and treatment $\times$ day interaction
Table 1. Influenza M1 mRNA expression

\begin{tabular}{lll}
\hline & Lung & Hippocampus \\
\hline CON day 1 & ND & ND \\
CON day 4 & ND & ND \\
CON day 7 & ND & ND \\
FLU day 1 & $1.64 \pm 0.93$ & ND \\
FLU day 4 & $54.55 \pm 5.3^{*}$ & ND \\
FLU day 7 & $20.16 \pm 3.5^{*}$ & ND
\end{tabular}

Influenza matrix (M1) protein mRNA expression in lung and brain tissue. Influenza M1 mRNA expression was measured in lung and hippocampal tissue at days 1, 4, and 7 following inoculation with influenza virus. As viral M1 was non-detectable (ND) in control lung samples, data are expressed as fold change in mRNA expression from day 1 after inoculation. Influenza $\mathrm{M} 1$ expression was elevated in the lungs of infected mice at day 4 and 7 after inoculation $\left({ }^{*} p<0.05\right.$ compared with day 1 after inoculation). Influenza M1 mRNA was nondetectable (ND) in hippocampal tissue from control or influenza-infected mice at any timepoint.

$(p<0.0001)$ indicating that following influenza infection, locomotor activity became increasingly depressed (Fig. 2 B). Overall, these data show that sickness behavior was first evident on day 3 after inoculation and as the disease progressed, both weight and locomotor activity declined until day 7 after inoculation when mice were killed. While the current study did not follow mice throughout recovery from infection, previous work using a 40 -fold higher (40 HAU) dose of influenza A/PR/8/34 demonstrated a $43 \%$ survival rate of adult $\mathrm{BALB} / \mathrm{c}$ mice (Lowder et al., 2005). These studies found that mice with substantial body weight loss $(30-35 \%)$ could recover from influenza infection. Real-time PCR was used to measure mRNA expression of influenza matrix (M1) protein in lung and brain tissue. Using the expression of this late viral gene product as a surrogate marker for virus replication (Fouchier et al., 2000), these data demonstrated that influenza M1 expression was detectable in the lungs by day 1 after inoculation and remained elevated at both day $4(p<0.001)$ and day $7(p=0.0034)$ after inoculation (Table 1). The decrease in influenza M1 expression from day 4 to day 7 after inoculation suggests that the mice are contending with the viral infection. Influenza M1 was nondetectable (ND) in control lung tissue or in hippocampal tissue from control or infected animals at any time point.

\section{Influenza infection impairs reversal learning in the Morris water maze}

In the MWM, a decrease in time (latency) to find the hidden platform or a decrease in pathlength (distance) to the platform, indicate an improvement in spatial learning and memory. Since latency to reach the platform can be affected by motor function (swim speed) and motivation, distance swam is considered a more reliable measure of learning and memory performance (Contet et al., 2001; Cunningham and Sanderson, 2008). As expected, mice infected with influenza showed reduced swim speeds over the course of MWM testing (data not shown); therefore distance to the platform was used to determine the performance of mice during both acquisition and reversal testing. For the acquisition data, repeated-measures ANOVA revealed an effect of day $(p<0.0001)$, but no effect of treatment $(p=0.406)$ or treatment $\times$ day interaction $(p=0.987)$, indicating that during acquisition, both control and infected mice demonstrated improved performance (shorter pathlength) over testing days and appear to acquire the task at the same rate (Fig. $3 A$ ). The results suggest that even though mice infected with influenza move slower, they are as "accurate" as control mice in locating the hidden platform. The results of the probe trial showed no difference $(p=0.916)$ in the amount of time influenza-infected mice spent in the target quadrant compared with controls (Fig. $3 B$ ). As both control and infected mice spent nearly $70 \%$ ( $25 \%$ is chance), 

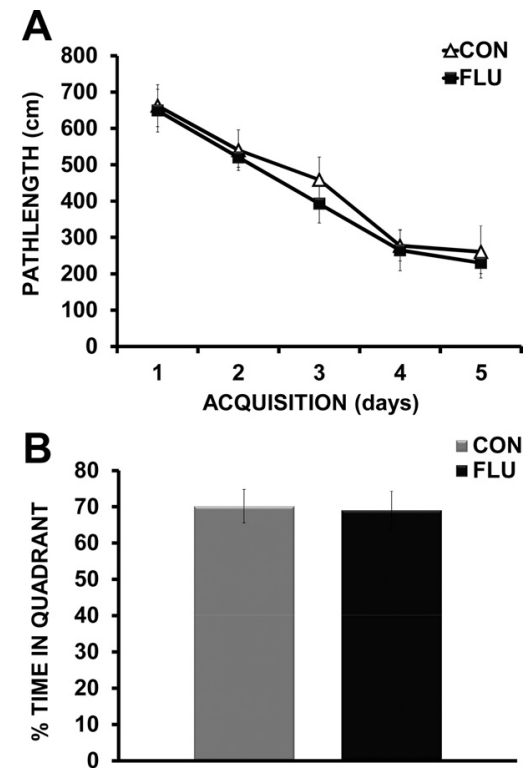

Figure 3. Morris water maze acquisition and probe trial. $A$, Influenza-infected (FLU) and control ( $C O N$ ) animals demonstrated similar performance during acquisition of the task as measured by distance to reach the hidden platform over $5 \mathrm{~d}$ of testing. $\boldsymbol{B}, \mathrm{A}$ probe trial $(24 \mathrm{~h}$ following the last day of acquisition testing) indicated no significant difference in the amount of time influenza mice spent in the target quadrant compared with controls.
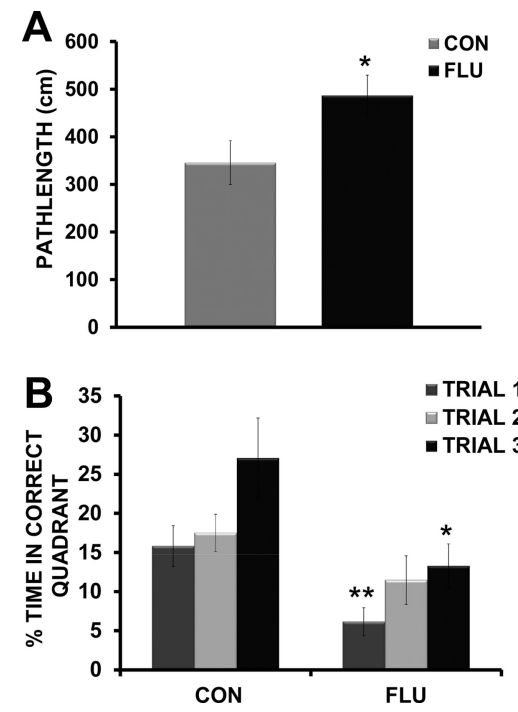

Figure 4. Morris water maze reversal testing. $\boldsymbol{A}$, Influenza-infected mice (FLU) demonstrated an increase in distance (pathlength) to reach the hidden platform when it was moved to the opposite quadrant during reversal testing. $\boldsymbol{B}$, Influenza-infected mice spent less time searching the correct target quadrant across trials during reversal testing when compared with control mice (CON). Data are represented as means \pm SEM $\left({ }^{*} p<0.05,{ }^{* *} p<0.01\right.$ compared with controls).

of their time in the correct quadrant, it is apparent that both groups learned and remembered the location of the hidden platform to a high degree. While influenza-infected mice were able to both acquire the task and remember the location of the hidden platform as well as controls, cognitive deficits were revealed during reversal testing. When the hidden platform was moved to the opposite quadrant, infected mice showed impaired ability to efficiently navigate to the new location as shown in by an increase in pathlength to the new platform location compared with controls $(p=0.037)$ (Fig. 4A). While all mice initially continued to search the location in which the platform was located during acquisition
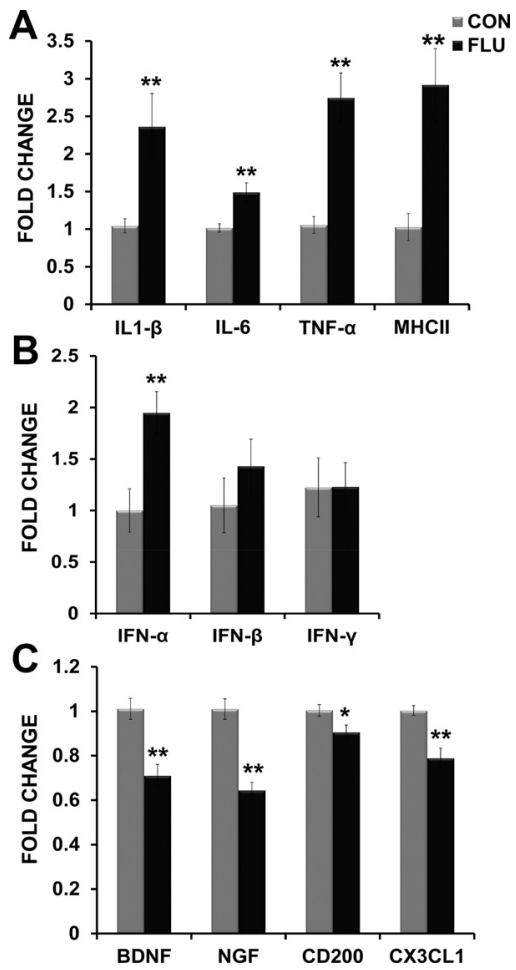

Figure 5. Influenza infection altered hippocampal gene expression. $\boldsymbol{A}$, Inflammatory cytokines (IL-1 $\beta$, IL-6, TNF- $\alpha$ ) and MHCII (marker of microglial activation) were increased in the hippocampus of influenza-infected mice. $\boldsymbol{B}$, Influenza infection induced increased hippocampal expression of antiviral cytokine IFN- $\alpha$. C, Neurotrophic (BDNF, NGF) and immunomodulatory factors (CD200, CX3CL1) were decreased in the hippocampus of influenza-infected mice (FLU). All data are from day 7 after inoculation. Data are represented as means \pm SEM $\left[{ }^{*} p<0.05,{ }^{* *} p<0.01\right.$ compared with controls $(\mathrm{CON})]$.

training, infected mice spent significantly more time returning to the incorrect quadrant (51\%) than controls (39\%) $(p=0.048)$ (data not shown), indicating increased perseverative behavior. Additional analysis of the reversal testing data used repeatedmeasures ANOVA to examine the effects of treatment (control vs flu) across trials for the time mice spent searching the correct quadrant location. There was a main effect of treatment $(p=$ 0.0057), indicating that control animals spent more time searching the correct quadrant during reversal testing, and a main effect of trial $(p=0.0098)$, with both control and influenza-infected mice increasing the time spent in the correct quadrant as trials progressed. Post hoc analysis showed that influenza-infected mice spent significantly less time searching the correct quadrant during both Trial $1(p=0.008)$ and Trial $3(p=0.034)$, suggesting a failure to update their search strategy when compared with control mice (Fig. 4B).

Influenza infection increases inflammatory cytokines and decreases neurotrophic and immunomodulatory factors Data in Figure $5 A$ show that expression levels of inflammatory cytokines IL- $1 \beta$ ( $p=0.008)$, IL-6 $(p=0.002)$, and TNF- $\alpha$ ( $p=$ 0.001 ) were elevated in the hippocampus of influenza-infected mice at day 7 after inoculation, the same time point in which cognitive impairment was evident. In addition, MHC-II, a marker of microglia activation (Kreutzberg, 1996; Lynch, 2009), was also upregulated ( $p=0.0002)$, suggesting that increased microglial activation may underlie this neuroinflammatory response. IFN- $\alpha$ was also increased in the hippocampus $(p=$ $0.004)$, but there was no effect of influenza infection on IFN- $\beta$ 
Table 2. Hippocampal gene expression at day 1 and 4 after inoculation

\begin{tabular}{llll}
\hline & CON & FLU day 1 & FLU day 4 \\
\hline IL-1 $\beta$ & $1.05 \pm 0.18$ & $1.08 \pm 0.12$ & $1.81 \pm 0.21^{*}$ \\
IL-6 & $1.04 \pm 0.16$ & $1.21 \pm 0.06$ & $1.57 \pm 0.08^{*}$ \\
TNF- $\alpha$ & $1.07 \pm 0.22$ & $1.11 \pm 0.12$ & $1.35 \pm 0.13$ \\
IFN- $\alpha$ & $1.01 \pm 0.07$ & $1.02 \pm 0.17$ & $1.62 \pm 0.32^{*}$ \\
BNDF & $1.01 \pm 0.09$ & $0.98 \pm 0.10$ & $0.94 \pm 0.11$ \\
NGF & $1.01 \pm 0.09$ & $1.04 \pm 0.04$ & $0.86 \pm 0.05$ \\
CD200 & $1.00 \pm 0.02$ & $1.05 \pm 0.02$ & $1.10 \pm 0.01^{*}$ \\
CX3CL1 & $1.00 \pm 0.02$ & $1.04 \pm 0.03$ & $0.88 \pm 0.03^{*}$
\end{tabular}

Changes in hippocampal gene expression at day 1 and day 4 after inoculation. Data are expressed as fold change in mRNA expression from controls. At day 1 after inoculation (FLU day 1), there was no effect of influenza infection on the expression of cytokines, neurotrophins, or immunomodulatory factors when compared with controls. At day 4 after inoculation (FLU day 4), inflammation was evident and there were alterations in the expression of immunomodulatory factors, but neurotrophic factor expression was unchanged. Data are represented as means \pm SEM $\left({ }^{*} p<0.05\right.$ compared with controls).

$(p=0.331)$ or IFN- $\gamma$ levels $(p=0.987)$ (Fig. $5 B)$. Influenza infection decreased hippocampal expression of neurotrophins $\operatorname{BDNF}(p=0.0003)$ and NGF $(p=0.0001)$, as well as immunomodulatory factors CD200 $(p=0.031)$ and CX3CL1 (fractalkine) $(p=0.0004)$ (Fig. $5 C)$. In addition, to better understand the timeframe in which alterations in neuron-microglia interactions may manifest during influenza infection, changes in the hippocampal expression of inflammatory, neurotrophic, and immunomodulatory factors were also assessed at day 1 and 4 after inoculation. There was no effect of influenza infection at day 1 after inoculation on the expression of any of the inflammatory cytokines, or neurotrophic and immunoregulatory factors (Table $2)$. At day 4 after inoculation, influenza infection induced a significant increase in IL-1 $\beta(p=0.0123)$, IL-6 $(p=0.0042)$, and IFN- $\alpha(p=0.0384)$, while there was no effect of influenza infection on the levels of TNF- $\alpha(p=0.2293)$ at this time point when compared with control mice. There was also no treatment effect at day 4 after inoculation for the expression of neurotrophic factors BDNF $(p=0.6173)$ or NGF $(p=0.1133)$, but CD200 was elevated $(p=0.0022)$, and CX3CL1 was reduced $(p=0.0034)$ in the hippocampus of infected mice when compared with controls (Table 2). It is possible that this early increase in CD200 is a compensatory mechanism to help control microglial activity as inflammation is increasing. Together, these findings suggest that an increase in hippocampal inflammation at day 4 after inoculation tends to precede the decrease in neurotrophic and immunomodulatory factors evident at day 7 after inoculation.

\section{Influenza infection increases microglia reactivity in the hippocampus}

To determine whether influenza infection altered microglial reactivity, the proportional area of Iba-1 immunostaining (area of positive thresholded material relative to the total area) was determined using digital image analysis. Data were subjected to a twoway ANOVA to examine the effects of treatment (control vs flu) across hippocampal region (DG, CA1, CA3). There was a main effect of influenza infection $(p=0.0003)$, but no effect of region $(p=0.544)$ or interaction $(p=0.992)$, indicating influenza increased Iba-1 expression throughout the hippocampus (Fig. $6 \mathrm{~A}$ ). As a difference in the area occupied by Iba-1 immunostaining could reflect a change in cell number, a change in cell size (morphology), or both, the number of Iba-1-positive cells and an estimate of their average size were also determined. For Iba-1-positive cell counts, there was a main effect of influenza infection $(p<0.0001)$, but no effect of region $(p=0.186)$ or interaction ( $p=0.821)$, indicating influenza increased the number if Iba-1-positive cells throughout the hippocampus (Fig. 6B).
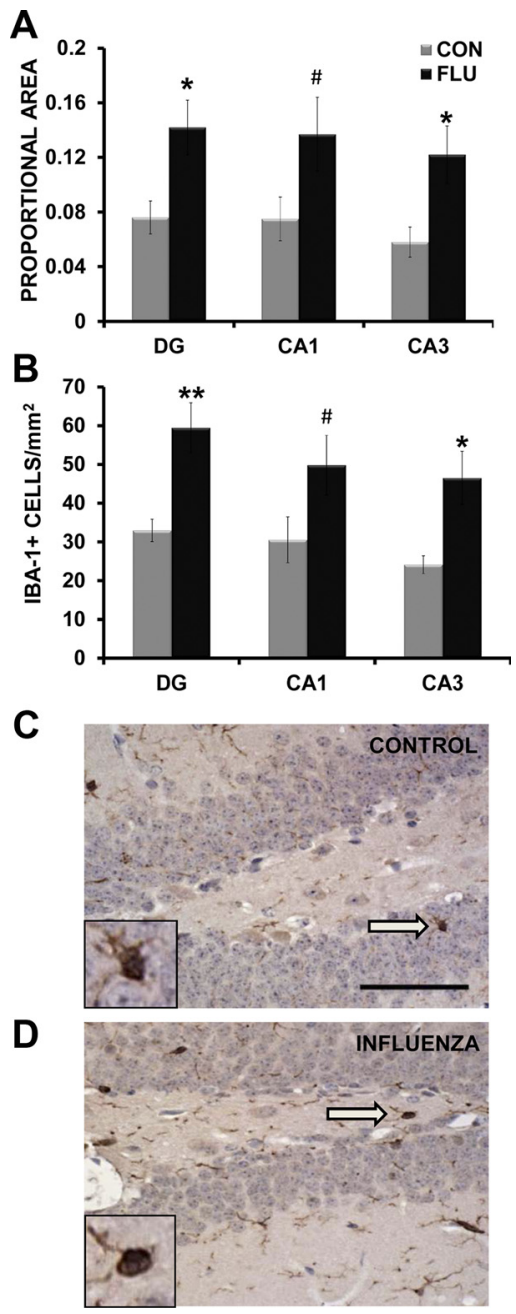

Figure 6. Influenza infection increased microglia reactivity. $\boldsymbol{A}$, Influenza infection increased the proportional area of $\mathrm{lba}-1$ staining in the hippocampus at day 7 after infection. $\boldsymbol{B}$, Influenza infection increased the number of Iba-1-positive cells in the hippocampus at day 7 after inoculation. $\boldsymbol{C}, \boldsymbol{D}$, Representative examples of Iba-1-positive cells in the dentate gyrus of a control (CON, $\boldsymbol{C}$ ) and influenza-infected (FLU, D) animal. Inset includes enlarged image of lba-1-positive cell indicated by arrow. Magnification $=40 \times$; scale bar, $50 \mu \mathrm{m}$. Data are represented as means \pm SEM $\left(^{*} p<0.05,{ }^{* *} p<0.01,{ }^{*} p=0.08\right.$ compared with controls).

There was no effect of influenza infection $(p=0.107)$ or region $(p=0.378)$ on the average size of Iba-1-positive cells (data not shown).

\section{Influenza infection alters hippocampal neuron morphology Dendritic arborization}

For CA1 pyramidal neurons, both the apical and basal trees were traced, and morphological measurements were analyzed separately. There was no effect of influenza infection on the total number of dendritic intersections in the apical $(p=0.434)$ or basal $(p=0.699)$ trees of CA1 pyramidal neurons (Fig. $7 A$ ). Further analysis of apical dendritic branching revealed an effect of influenza $(p<0.05)$ on the number of intersections at distances of $200-240 \mu \mathrm{m}$ from the soma (Fig. $7 B$ ), suggesting influenza-induced alterations in the distal portion of the apical tree. Morphological analyses of the CA1 basal tree found that influenza infection did not alter dendritic branching patterns as determined by Sholl analysis (data not shown).

For dentate gyrus granule cells, a two-way ANOVA revealed a main effect of soma location in the GCL (inner vs outer GCL) $(p=0.0023)$ and treatment (control vs flu) $(p=0.049)$, indicat- 

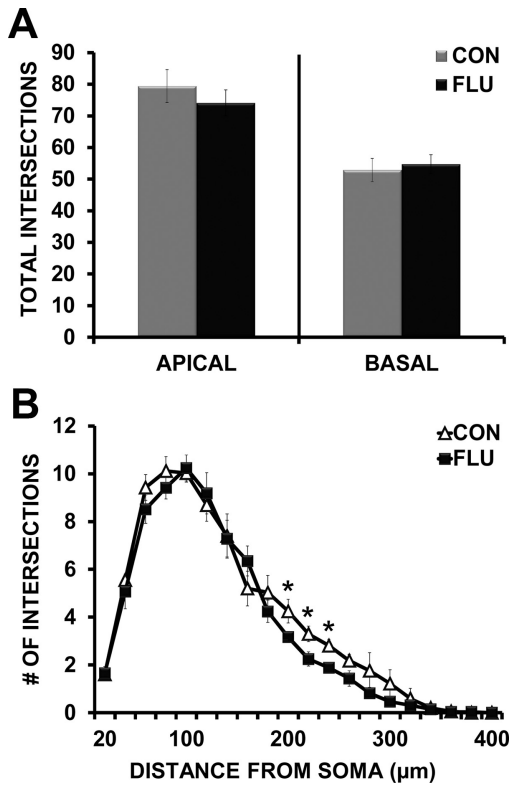

Figure 7. Influenza infection altered CA1 pyramidal neuron morphology. $A$, Influenza infection (FLU) did not affect the total number of apical or basal tree dendritic intersections of CA1 pyramidal neurons. $\boldsymbol{B}$, Influenza infection induced retraction of dendrites in the distal portion of the CA1 apical tree (reduced intersections $200-240 \mu \mathrm{m}$ from the soma). Data are represented as means \pm SEM $\left[{ }^{*} p<0.05\right.$ compared with controls $\left.(\mathrm{CON})\right]$.

ing less arborization of dentate granule cells (DGCs) in the innermost portion of GCL, and an influenza-induced decrease in dendritic extent to some degree in both populations. Post hoc analysis showed that when separated out by soma location, only cells located in the outer portion of the GCL demonstrated a reduction in total intersections $(p=0.028)$ following influenza infection when compared with controls (Fig. 8A). Because we found a main effect of soma location (inner vs outer GCL) on total dendritic intersections, and previous work has shown that the morphology of dentate gyrus granule neurons varies by soma location within the granule cell layer (Green and Juraska, 1985; Wang et al., 2000), dentate granule cells were separated based on soma location (inner vs outer GCL) for further morphological analysis of dendritic arbors. For dentate granule neurons in both the inner and outer portion of the granule cell layer, repeatedmeasures ANOVA revealed an interaction $(p<0.0001)$ between treatment (control vs influenza) and interval distance from the soma $(\mu \mathrm{m})$, indicating that influenza infection altered the shape of the dendritic tree in both of these subpopulations (Fig. $8 B, C$ ). The altered dendritic arborization of inner DGCs was due to a retraction in the distal dendrites $(160-220 \mu \mathrm{m}$ from the soma) $(p<0.05)$ and an increase in dendritic extent near the soma $(40-80 \mu \mathrm{m}$ from the soma) $(p<0.05)$ in influenza mice when compared with controls (Fig. $8 \mathrm{~B}$ ). For dentate granule neurons located in the outer portion of the GCL, influenza infection induced a retraction of dendrites in both the middle and distal $(140-200 \mu \mathrm{m}$ from the soma) $(p<0.05)$ regions of the dendritic tree (Fig. $8 C$ ).

\section{Dendritic spine density}

For CA1 pyramidal neurons, spine density was calculated and analyzed separately for apical and basal dendritic trees. Influenza infection did not alter the spine density of CA1 apical or basal dendrites (Fig. 9B). For dentate granule neurons, a two-way ANOVA determined the effect of location in the GCL (inner vs
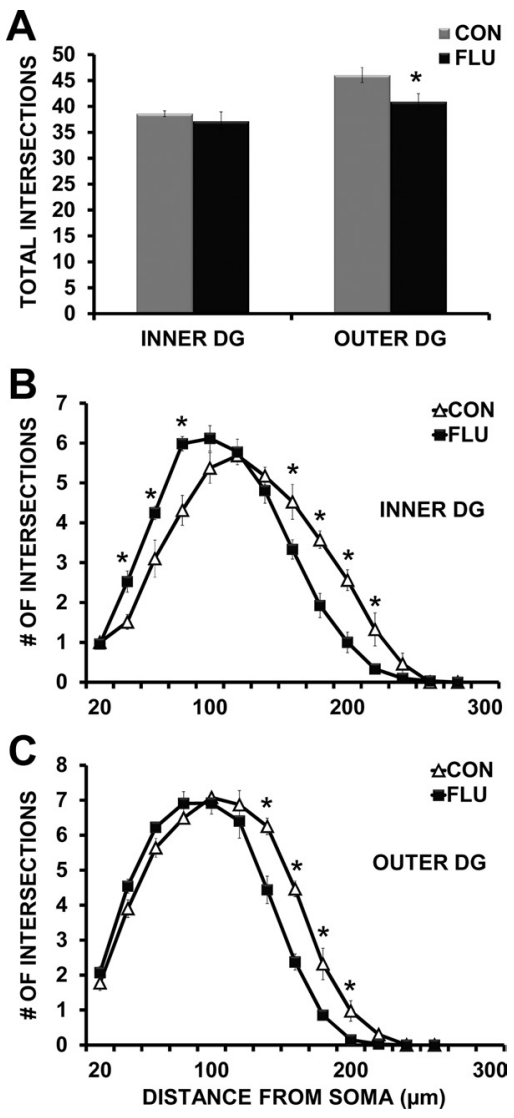

Figure 8. Influenza infection altered dentate granule neuron morphology. $\boldsymbol{A}$, Influenza infection (FLU) reduced the total number of dendritic intersections of dentate granuleneurons in the outerportion of the $\mathrm{GCL}$. $\boldsymbol{B}$, Influenza infection induced retraction of distal dendrites (160-220 $\mu \mathrm{m}$ from the soma) while increasing dendritic extent proximal to the cell body ( $40-80 \mu \mathrm{m}$ from the soma) of dentate granule neurons residing in the inner portion of the $\mathrm{GCL}$. $\boldsymbol{C}$, Influenza infection induced retraction of distal dendrites (140-200 $\mu \mathrm{m}$ from the soma) of dentate granule cells located in the outer portion of the $\mathrm{GCL}$. Data are represented as means \pm SEM $\left[{ }^{*} p<0.05\right.$ compared with controls (CON)].

outer) and treatment (control vs influenza) on dendritic spine density. There was a main effect of location $(p=0.0013)$ with overall increased dendritic spine density on cells in the outer dentate gyrus. In addition, a treatment by location interaction $(p=0.0274)$ suggested that the effects of influenza on spine density differed by soma location. Post hoc analysis revealed that dentate granule cells residing in the inner portion of the GCL had reduced spine density ( $p=0.0138$ ) following influenza infection, while cells in the outer portion of the GCL were not affected ( $p=$ 0.5563) (Fig. 9C).

\section{Discussion}

The current study determined the impact of peripheral influenza infection on the neuroimmune response, hippocampal neuron morphology, and cognitive function of adult mice. Infected mice exhibited cognitive impairment during reversal learning that was paralleled by increased hippocampal expression of proinflammatory cytokines and the loss of neurotrophic and immunomodulatory factors. Increased microglia reactivity and alterations in neuronal architecture were evident in the hippocampus at the same time point in which cognitive deficits were apparent. These data are the first to show that influenza infection induces hippocampal inflammation and alters neuron morphology in the CA1 and dentate gyrus. Changes in hippocampal structural plas- 


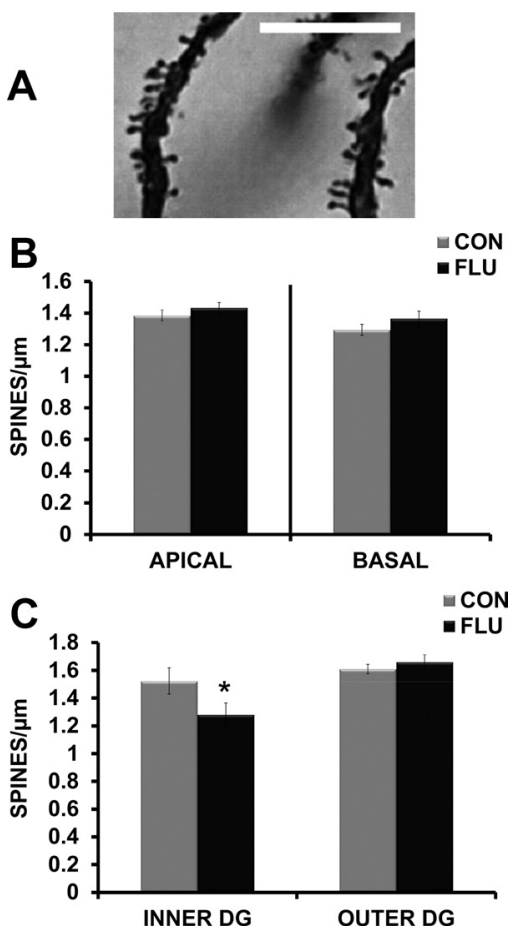

Figure 9. Effects of influenza infection on spine density of hippocampal dendrites. $\boldsymbol{A}$, Representative image of Golgi-stained dendritic spines in the dentate gyrus. Magnification = $100 \times$; scale bar, $10 \mu \mathrm{m}$. $\boldsymbol{B}$, Influenza infection (FLU) did not alter spine density of apical or basal dendrites in the CA1 region. $\boldsymbol{C}$, Influenza infection decreased dendritic spine density of dentate granule cells located in the inner portion of the $\mathrm{GCL}$. Data are represented as means \pm SEM $\left[{ }^{*} p<0.05\right.$ compared with controls (CON)].

ticity may underlie the deleterious effects of influenza on cognitive function.

\section{Effects of influenza infection on cognitive function}

Influenza-induced cognitive deficits were revealed during reversal testing when infected mice showed impaired ability to efficiently navigate to the new platform location. Overall, the infected mice demonstrated a failure to update their search strategy and increased perseverative behavior when compared with control mice. This pattern of behavior resembles previous work showing that hippocampal-lesioned animals can acquire a place response in the water maze, but are impaired during reversal learning due to perseverative returns to the previous correct location (Whishaw and Tomie, 1997; Whishaw, 1998). Thus, the present results indicate that influenza infection inhibited normal hippocampal function. While hippocampal damage can disrupt spatial reversal learning, regions including the frontal cortex (Kesner and Churchwell, 2011) and striatum (Wei et al., 2011) are also involved, and could be additional targets of influenza infection.

\section{Effects of influenza infection on hippocampal gene expression}

At the same time point in which cognitive deficits were evident, proinflammatory and anti-viral mediators (IL- $1 \beta$, IL-6,TNF- $\alpha$, MHC-II, and IFN- $\alpha$ ) were elevated in the hippocampus of influenza-infected mice, indicating neuroinflammation and microglial activation in a region relevant to spatial learning and memory. Although cytokines induced by LPS, and in particular IL- $1 \beta$, are known to alter cognition (McAfoose and Baune, 2009; Yirmiya and Goshen, 2011), less is known regarding the behav- ioral effects of virally induced interferons. Interferon therapy in humans has adverse neuropsychological effects, including memory alterations and depression (Valentine et al., 1998; Capuron and Miller, 2004). In rodents, IFN- $\alpha$ can alter cognitive function, with overexpression resulting in neuroinflammation and neurodegeneration (Campbell et al., 1999; Sas et al., 2007, 2009). While the type-I interferon response is crucial to control viral infection in the periphery (Wolff and Ludwig, 2009), increased hippocampal expression of IFN- $\alpha$ during influenza infection could contribute to cognitive dysfunction and neuronal damage.

Concurrent with increased inflammation, neurotrophic factors (BDNF, NGF) were decreased in the hippocampus of infected mice. These findings are similar to previous work demonstrating reduced neurotrophins in the hippocampus of both adult and aged rodents following peripheral administration of LPS or E. coli infection (Guan and Fang, 2006; Richwine et al., 2008; Chapman et al., 2012). The loss of neurotrophic factors essential to neuron survival and function (Poo, 2001; Chao, 2003; Minichiello, 2009) could contribute to cognitive impairment and leave the brain vulnerable during influenza infection.

Although neurotrophic factors are well known for their role in neuron support and survival, they also help maintain microglia in a resting state (Neumann et al., 1998). Healthy neurons maintain microglia in a quiescent state via signals including CD200, CX3CL1, neurotransmitters, and neurotrophins (Biber et al., 2008; Tian et al., 2009). Immunomodulatory factors CD200 and CX3CL1 are constitutively expressed in the brain and play an important role in downregulating inflammation and microglial activation during aging, stress and disease (Hoek et al., 2000; Cardona et al., 2006; Frank et al., 2007; Wynne et al., 2010; Jurgens and Johnson, 2012). The time course of changes in the hippocampal microenvironment during influenza suggests that a neuroinflammatory state tends to precede the decrease in mediators of neuronal support and function. By day 7 after infection, the loss of neurotrophins, along with reduced expression of CD200 and CX3CL1, could impede neuron-microglia interactions and contribute to increased inflammation and microglial activation. Influenza-induced loss of this cross talk could have detrimental effects on neuronal function as it has been shown that CD200-deficiency impairs hippocampal synaptic plasticity (Costello et al., 2011).

\section{Effects of influenza infection on microglial reactivity}

While termed "resting," microglia in the healthy adult brain play an active role in maintaining CNS integrity by continuously scanning the brain parenchyma for alterations in homeostasis and monitoring the functional state of synapses (Nimmerjahn et al., 2005; Wake et al., 2009). Sensitive to changes in their microenvironment, microglia respond by entering different activation states that are dependent on the nature and duration of the stimulus (Hanisch and Kettenmann, 2007; Ransohoff and Perry, 2009). Although microglia activation is necessary for host defense, prolonged or aberrant activation can have damaging effects (Block et al., 2007).

The loss of glial regulatory factors along with increased expression of MHC-II in the hippocampus suggests that influenza may increase microglial reactivity. To investigate this further, we used immunohistochemistry to measure Iba- 1 expression in the hippocampus. Iba- 1 is expressed by microglia and upregulated in response to immune-activating stimuli including stress, aging, and inflammation (Ito et al., 1998; Choi et al., 2007; Chung et al., 2010; Tynan et al., 2010). Our results show that Iba-1 expression was increased throughout the hippocampus of influenza-infected 
mice. The increase in proportional area of Iba- 1 expression was driven by an increased number of Iba-1-positive cells, as the average cell size was not altered by influenza infection.

An increase in the number of Iba-1-positive cells could be due to proliferation of microglia as shown during stress or injury (Dihné et al., 2001; Nair and Bonneau, 2006; Ajami et al., 2007), or due to an increase in Iba-1 expression that allowed cells previously below the level of detection to become detectable (Tynan et al., 2010). Although specific analyses of cell surface markers would be needed to determine whether Iba-1-positive cells were resident microglia versus trafficking CNS macrophages (Mildner et al., 2007; Ransohoff and Perry, 2009), the overall increase in Iba-1 expression indicates an altered neuroimmune response during influenza infection.

\section{Effects of influenza infection on hippocampal neuron morphology}

To better understand potential cellular mechanisms associated with the central effects of influenza infection, changes in hippocampal neuronal architecture were assessed at the time point in which neuroinflammation and cognitive deficits were evident. Results showed that while both CA1 pyramidal neurons and dentate granule neurons demonstrated retraction of distal dendrites following infection, the architecture of granule cells was more profoundly affected.

Previous work has shown that the morphology of granule neurons varies by soma location within the GCL (Green and Juraska, 1985; Wang et al., 2000). We found that influenza differentially affected DGCs residing in the inner versus the outer portions of the GCL. Influenza infection induced a significant loss of distal dendrites in both subpopulations, but only neurons located in the inner GCL demonstrated increased proximal branching. These data indicated overall dendritic atrophy in outer DGCs, while inner DGCs showed evidence of dendritic reorganization.

Along with different structural features, soma location is also associated with the "age" of the neuron, with the inner third of the GCL containing a high proportion of neurons generated during adult neurogenesis, while the outer layers contain mostly mature neurons generated during development (Espósito et al., 2005; Mathews et al., 2010; Mongiat and Schinder, 2011). While the methods used here do not allow for determination of neuron maturity, it is possible the microenvironment of the innermost GCL, with continuous network remodeling due to the addition of adult-born neurons (Mongiat and Schinder, 2011), could influence the structural plasticity of existing neurons (both immature and mature) within this region. Increased dendritic branching near the soma of inner DGCs could be a compensatory mechanism aimed at maintaining overall synaptic contact following the loss of distal dendrites and reduction in spine density induced by influenza infection.

While it is unknown whether alterations in dendritic branching are indicative of protective or pathological remodeling (McEwen, 2010), changes in the structural plasticity of both the CA1 and dentate gyrus could impact hippocampal function and cognitive behavior during influenza infection. Previous work using central injection of LPS found significant changes in hippocampal neuron morphology without cell loss (Milatovic et al., 2003), suggesting that altered neuronal structure during inflammatory conditions, as opposed to cell death, likely underlies behavioral changes.

It is hypothesized that (over a lifetime), common respiratory viruses, such as influenza, can induce cumulative neuroinflammatory damage leaving the brain less resilient to future insult and contributing to neurodegeneration (Majde, 2010). The results of this study are the first direct evidence that peripheral infection with influenza induces neuroinflammation and alterations in the structural plasticity of the hippocampus, a brain region essential to cognition and vulnerable to degeneration. While the present work focused on the central effects of influenza infection during acute sickness, studies are underway to determine whether these changes persist following recovery. A better understanding of how peripheral viral infection alters the structure and function of the CNS will allow for the development of therapeutic strategies aimed at modulating the neuroimmune response and maintaining neuronal integrity.

\section{References}

Ajami B, Bennett JL, Krieger C, Tetzlaff W, Rossi FM (2007) Local selfrenewal can sustain CNS microglia maintenance and function throughout adult life. Nat Neurosci 10:1538-1543.

Biber K, Vinet J, Boddeke HW (2008) Neuron-microglia signaling: chemokines as versatile messengers. J Neuroimmunol 198:69-74.

Bird CM, Burgess N (2008) The hippocampus and memory: insights from spatial processing. Nat Rev Neurosci 9:182-194.

Block ML, Zecca L, Hong JS (2007) Microglia-mediated neurotoxicity: uncovering the molecular mechanisms. Nat Rev Neurosci 8:57-69.

Campbell IL, Krucker T, Steffensen S, Akwa Y, Powell HC, Lane T, Carr DJ, Gold LH, Henriksen SJ, Siggins GR (1999) Structural and functional neuropathology in transgenic mice with CNS expression of IFN-alpha. Brain Res 835:46-61.

Capuron L, Miller AH (2004) Cytokines and psychopathology: lessons from interferon-alpha. Biol Psychiatry 56:819-824.

Cardona AE, Pioro EP, Sasse ME, Kostenko V, Cardona SM, Dijkstra IM, Huang D, Kidd G, Dombrowski S, Dutta R, Lee JC, Cook DN, Jung S, Lira SA, Littman DR, Ransohoff RM (2006) Control of microglial neurotoxicity by the fractalkine receptor. Nat Neurosci 9:917-924.

Centers for Disease Control and Prevention (CDC) (2009) Neurologic complications associated with novel influenza A (H1N1) virus infection in children-Dallas, May 2009. MMWR Morb Mortal Wkly Rep 58:773-778.

Chao MV (2003) Neurotrophins and their receptors: a convergence point for many signalling pathways. Nat Rev Neurosci 4:299-309.

Chapman TR, Barrientos RM, Ahrendsen JT, Hoover JM, Maier SF, Patterson SL (2012) Aging and infection reduce expression of specific brainderived neurotrophic factor mRNAs in hippocampus. Neurobiol Aging 33:832.e1-832.e14.

Chen J, Buchanan JB, Sparkman NL, Godbout JP, Freund GG, Johnson RW (2008) Neuroinflammation and disruption in working memory in aged mice after acute stimulation of the peripheral innate immune system. Brain Behav Immun 22:301-311.

Choi JH, Lee CH, Hwang IK, Won MH, Seong JK, Yoon YS, Lee HS, Lee IS (2007) Age-related changes in ionized calcium-binding adapter molecule 1 immunoreactivity and protein level in the gerbil hippocampal CA1 region. J Vet Med Sci 69:1131-1136.

Chung DW, Yoo KY, Hwang IK, Kim DW, Chung JY, Lee CH, Choi JH, Choi SY, Youn HY, Lee IS, Won MH (2010) Systemic administration of lipopolysaccharide induces cyclooxygenase- 2 immunoreactivity in endothelium and increases microglia in the mouse hippocampus. Cell $\mathrm{Mol}$ Neurobiol 30:531-541.

Contet C, Rawlins JN, Bannerman DM (2001) Faster is not surer-a comparison of C57BL/6J and 129S2/Sv mouse strains in the watermaze. Behav Brain Res 125:261-267.

Costello DA, Lyons A, Denieffe S, Browne TC, Cox FF, Lynch MA (2011) Long-term potentiation is impaired in CD200-deficient mice: a role for Toll-like receptor. J Biol Chem 286:34722-34732.

Cunningham C, Sanderson DJ (2008) Malaise in the water maze: untangling the effects of LPS and IL-1beta on learning and memory. Brain Behav Immun 22:1117-1127.

Dantzer R, O'Connor JC, Freund GG, Johnson RW, Kelley KW (2008) From inflammation to sickness and depression: when the immune system subjugates the brain. Nat Rev Neurosci 9:46-56.

D’Hooge R, De Deyn PP (2001) Applications of the Morris water maze in the study of learning and memory. Brain Res Brain Res Rev 36:60-90.

Dihné M, Block F, Korr H, Töpper R (2001) Time course of glial prolifera- 
tion and glial apoptosis following excitotoxic CNS injury. Brain Res 902:178-189.

Donnelly DJ, Gensel JC, Ankeny DP, van Rooijen N, Popovich PG (2009) An efficient and reproducible method for quantifying macrophages in different experimental models of central nervous system pathology. J Neurosci Methods 181:36-44.

Espósito MS, Piatti VC, Laplagne DA, Morgenstern NA, Ferrari CC, Pitossi FJ, Schinder AF (2005) Neuronal differentiation in the adult hippocampus recapitulates embryonic development. J Neurosci 25:10074-10086.

Fouchier RA, Bestebroer TM, Herfst S, Van Der Kemp L, Rimmelzwaan GF, Osterhaus AD (2000) Detection of influenza A viruses from different species by PCR amplification of conserved sequences in the matrix gene. J Clin Microbiol 38:4096-4101.

Frank MG, Baratta MV, Sprunger DB, Watkins LR, Maier SF (2007) Microglia serve as a neuroimmune substrate for stress-induced potentiation of CNS pro-inflammatory cytokine responses. Brain Behav Immun 21: 47-59.

Glaser EM, Van der Loos H (1981) Analysis of thick brain sections by obverse-reverse computer microscopy: application of a new, high clarity Golgi-Nissl stain. J Neurosci Methods 4:117-125.

González-Duarte A, Magaña Zamora L, Cantú Brito C, García-Ramos G (2010) Hypothalamic abnormalities and Parkinsonism associated with H1N1 influenza infection. J Neuroinflammation 7:47.

Gould E, Woolley CS, Frankfurt M, McEwen BS (1990) Gonadal steroids regulate dendritic spine density in hippocampal pyramidal cells in adulthood. J Neurosci 10:1286-1291.

Green EJ, Juraska JM (1985) The dendritic morphology of hippocampal dentate granule cells varies with their position in the granule cell layer: a quantitative Golgi study. Exp Brain Res 59:582-586.

Guan Z, Fang J (2006) Peripheral immune activation by lipopolysaccharide decreases neurotrophins in the cortex and hippocampus in rats. Brain Behav Immun 20:64-71.

Hanisch UK, Kettenmann H (2007) Microglia: active sensor and versatile effector cells in the normal and pathologic brain. Nat Neurosci 10:1387-1394.

Hoek RM, Ruuls SR, Murphy CA, Wright GJ, Goddard R, Zurawski SM, Blom B, Homola ME, Streit WJ, Brown MH, Barclay AN, Sedgwick JD (2000) Down-regulation of the macrophage lineage through interaction with OX2 (CD200). Science 290:1768-1771.

Ito D, Imai Y, Ohsawa K, Nakajima K, Fukuuchi Y, Kohsaka S (1998) Microglia-specific localisation of a novel calcium binding protein, Ibal. Brain Res Mol Brain Res 57:1-9.

Jurgens HA, Johnson RW (2012) Dysregulated neuronal-microglial crosstalk during aging, stress and inflammation. Exp Neurol 233:40-48.

Kasai H, Fukuda M, Watanabe S, Hayashi-Takagi A, Noguchi J (2010) Structural dynamics of dendritic spines in memory and cognition. Trends Neurosci 33:121-129.

Kesner RP, Churchwell JC (2011) An analysis of rat prefrontal cortex in mediating executive function. Neurobiol Learn Mem 96:417-431.

Kobasa D, Jones SM, Shinya K, Kash JC, Copps J, Ebihara H, Hatta Y, Kim JH, Halfmann P, Hatta M, Feldmann F, Alimonti JB, Fernando L, Li Y, Katze MG, Feldmann H, Kawaoka Y (2007) Aberrant innate immune response in lethal infection of macaques with the 1918 influenza virus. Nature 445:319-323.

Kreutzberg GW (1996) Microglia: a sensor for pathological events in the CNS. Trends Neurosci 19:312-318.

Leuner B, Gould E (2010) Structural plasticity and hippocampal function. Annu Rev Psychol 61:111-140, C1-3.

Lowder T, Padgett DA, Woods JA (2005) Moderate exercise protects mice from death due to influenza virus. Brain Behav Immun 19:377-380.

Lynch MA (2002) Interleukin-1 beta exerts a myriad of effects in the brain and in particular in the hippocampus: analysis of some of these actions. Vitam Horm 64:185-219.

Lynch MA (2009) The multifaceted profile of activated microglia. Mol Neurobiol 40:139-156.

Majde JA (2010) Neuroinflammation resulting from covert brain invasion by common viruses - a potential role in local and global neurodegeneration. Medical Hypotheses 75:204-213.

Markham JA, McKian KP, Stroup TS, Juraska JM (2005) Sexually dimorphic aging of dendritic morphology in CA1 of hippocampus. Hippocampus 15:97-103.

Mathews EA, Morgenstern NA, Piatti VC, Zhao C, Jessberger S, Schinder AF,
Gage FH (2010) A distinctive layering pattern of mouse dentate granule cells is generated by developmental and adult neurogenesis. J Comp Neurol 518:4479-4490.

Matsuoka Y, Lamirande EW, Subbarao K (2009) The mouse model for influenza. Curr Protoc Microbiol Chapter 15:Unit 15G.3.

McAfoose J, Baune BT (2009) Evidence for a cytokine model of cognitive function. Neurosci Biobehav Rev 33:355-366.

McEwen BS (2010) Stress, sex, and neural adaptation to a changing environment: mechanisms of neuronal remodeling. Ann N Y Acad Sci 1204 [Suppl]:E38-E59.

Milatovic D, Zaja-Milatovic S, Montine KS, Horner PJ, Montine TJ (2003) Pharmacologic suppression of neuronal oxidative damage and dendritic degeneration following direct activation of glial innate immunity in mouse cerebrum. J Neurochem 87:1518-1526.

Mildner A, Schmidt H, Nitsche M, Merkler D, Hanisch UK, Mack M, Heikenwalder M, Brück W, Priller J, Prinz M (2007) Microglia in the adult brain arise from Ly-6ChiCCR ${ }^{2+}$ monocytes only under defined host conditions. Nat Neurosci 10:1544-1553.

Minichiello L (2009) TrkB signalling pathways in LTP and learning. Nat Rev Neurosci 10:850-860.

Mongiat LA, Schinder AF (2011) Adult neurogenesis and the plasticity of the dentate gyrus network. Eur J Neurosci 33:1055-1061.

Morris RG (1984) Developments of a water-maze procedure for studying spatial learning in the rat. J Neurosci Methods 11:47-60.

Nair A, Bonneau RH (2006) Stress-induced elevation of glucocorticoids increases microglia proliferation through NMDA receptor activation. J Neuroimmunol 171:72-85.

Neumann H, Misgeld T, Matsumuro K, Wekerle H (1998) Neurotrophins inhibit major histocompatibility class II inducibility of microglia: involvement of the p75 neurotrophin receptor. Proc Natl Acad Sci U S A 95:5779-5784.

Neves G, Cooke SF, Bliss TV (2008) Synaptic plasticity, memory and the hippocampus: a neural network approach to causality. Nat Rev Neurosci 9:65-75.

Nimmerjahn A, Kirchhoff F, Helmchen F (2005) Resting microglial cells are highly dynamic surveillants of brain parenchyma in vivo. Science 308:1314-1318

Nogusa S, Ritz BW, Kassim SH, Jennings SR, Gardner EM (2008) Characterization of age-related changes in natural killer cells during primary influenza infection in mice. Mech Ageing Dev 129:223-230.

Olfert ED, Godson DL (2000) Humane endpoints for infectious disease animal models. ILAR J 41:99-104.

Pickering M, O’Connor JJ (2007) Pro-inflammatory cytokines and their effects in the dentate gyrus. Prog Brain Res 163:339-354.

Poo MM (2001) Neurotrophins as synaptic modulators. Nat Rev Neurosci 2:24-32.

Ransohoff RM, Perry VH (2009) Microglial physiology: unique stimuli, specialized responses. Annu Rev Immunol 27:119-145.

Ravenholt RT, Foege WH (1982) 1918 influenza, encephalitis lethargica, parkinsonism. Lancet 2:860-864.

Richwine AF, Parkin AO, Buchanan JB, Chen J, Markham JA, Juraska JM, Johnson RW (2008) Architectural changes to CAl pyramidal neurons in adult and aged mice after peripheral immune stimulation. Psychoneuroendocrinology 33:1369-1377.

Sas AR, Bimonte-Nelson HA, Tyor WR (2007) Cognitive dysfunction in HIV encephalitic SCID mice correlates with levels of Interferon-alpha in the brain. AIDS 21:2151-2159.

Sas AR, Bimonte-Nelson H, Smothers CT, Woodward J, Tyor WR (2009) Interferon- $\alpha$ causes neuronal dysfunction in encephalitis. J Neurosci 29:3948-3955.

Schlesinger RW, Husak PJ, Bradshaw GL, Panayotov PP (1998) Mechanisms involved in natural and experimental neuropathogenicity of influenza viruses: evidence and speculation. Adv Virus Res 50:289-379.

Schmittgen TD, Livak KJ (2008) Analyzing real-time PCR data by the comparative C(T) method. Nat Protoc 3:1101-1108.

Sparkman NL, Buchanan JB, Heyen JR, Chen J, Beverly JL, Johnson RW (2006) Interleukin-6 facilitates lipopolysaccharide-induced disruption in working memory and expression of other proinflammatory cytokines in hippocampal neuronal cell layers. J Neurosci 26:10709-10716.

Studahl M (2003) Influenza virus and CNS manifestations. J Clin Virol 28:225-232. 
Tian L, Rauvala H, Gahmberg CG (2009) Neuronal regulation of immune responses in the central nervous system. Trends Immunol 30:91-99.

Tong L, Balazs R, Soiampornkul R, Thangnipon W, Cotman CW (2008) Interleukin-1 beta impairs brain derived neurotrophic factor-induced signal transduction. Neurobiol Aging 29:1380-1393.

Tyler WJ, Alonso M, Bramham CR, Pozzo-Miller LD (2002) From acquisition to consolidation: on the role of brain-derived neurotrophic factor signaling in hippocampal-dependent learning. Learn Mem 9:224-237.

Tynan RJ, Naicker S, Hinwood M, Nalivaiko E, Buller KM, Pow DV, Day TA, Walker FR (2010) Chronic stress alters the density and morphology of microglia in a subset of stress-responsive brain regions. Brain Behav Immun 24:1058-1068.

Valentine AD, Meyers CA, Kling MA, Richelson E, Hauser P (1998) Mood and cognitive side effects of interferon-alpha therapy. Semin Oncol 25:39-47.

Vitkovic L, Konsman JP, Bockaert J, Dantzer R, Homburger V, Jacque C (2000) Cytokine signals propagate through the brain. Mol Psychiatry 5:604-615.

Vorhees CV, Williams MT (2006) Morris water maze: procedures for assessing spatial and related forms of learning and memory. Nat Protoc $1: 848-858$

Wake H, Moorhouse AJ, Jinno S, Kohsaka S, Nabekura J (2009) Resting microglia directly monitor the functional state of synapses in vivo and determine the fate of ischemic terminals. J Neurosci 29:3974-3980.
Wang GF, Li W, Li K (2010) Acute encephalopathy and encephalitis caused by influenza virus infection. Curr Opin Neurol 23:305-311.

Wang S, Scott BW, Wojtowicz JM (2000) Heterogenous properties of dentate granule neurons in the adult rat. J Neurobiol 42:248-257.

Ward CL, Dempsey MH, Ring CJ, Kempson RE, Zhang L, Gor D, Snowden BW, Tisdale M (2004) Design and performance testing of quantitative real time PCR assays for influenza A and B viral load measurement. J Clin Virol 29:179-188.

Wei CJ, Singer P, Coelho J, Boison D, Feldon J, Yee BK, Chen JF (2011) Selective inactivation of adenosine $\mathrm{A}(2 \mathrm{~A})$ receptors in striatal neurons enhances working memory and reversal learning. Learn Mem 18: $459-474$.

Whishaw IQ (1998) Place learning in hippocampal rats and the path integration hypothesis. Neurosci Biobehav Rev 22:209-220.

Whishaw IQ, Tomie J (1997) Perseveration on place reversals in spatial swimming pool tasks: further evidence for place learning in hippocampal rats. Hippocampus 7:361-370.

Wolff T, Ludwig S (2009) Influenza viruses control the vertebrate type I interferon system: factors, mechanisms, and consequences. J Interferon Cytokine Res 29:549-557.

Wynne AM, Henry CJ, Huang Y, Cleland A, Godbout JP (2010) Protracted downregulation of CX(3)CR1 on microglia of aged mice after lipopolysaccharide challenge. Brain Behav Immun 24:1190-1201.

Yirmiya R, Goshen I (2011) Immune modulation of learning, memory, neural plasticity and neurogenesis. Brain Behav Immun 25:181-213. 